\title{
TEMPOS E ESPACִOS NA ORGANIZAÇÃO CURRICULAR: UMA REFLEXÃO SOBRE A DINÂMICA DOS PROCESSOS ESCOLARES
}

\author{
Juares da Silva Thiesen*
}

RESUMO: O presente artigo apresenta uma reflexão sobre os conceitos de tempo e espaço na organização curricular com ênfase na dinâmica dos processos escolares. Destaca inicialmente como essas categorias foram concebidas durante a modernidade sob a influência do pensamento mecanicista/positivista, apontando as críticas que alguns pesquisadores atuais fazem dessa concepção. $\mathrm{O}$ texto argumenta em defesa de uma releitura desses mesmos conceitos na contemporaneidade, releitura essa que pode se traduzir em mudanças significativas nas formas de organização curricular na atualidade. Defende que a releitura dos conceitos de tempo e espaço curricular está sendo estimulada em contextos que incluem a democratização da informação via WWW, a globalização econômica, o desenvolvimento das tecnologias da informação e comunicação, a expansão da educação a distância e, muito expressivamente, as contribuições trazidas pelas atuais abordagens sobre currículo e sobre infância.

Palavras-chave: Tempo; Espaço; Currículo.

TIMES AND SPACES IN THE CURRICULAR ORGANIZATION:

A REFLECTION ABOUT ON THE DYNAMICS OF SCHOOL PROCESSES

ABSTRACT: The present article presents an overview of concepts of time and space in the curricular organization, with focus on the dynamics of schooling processes. It initially highlights how these aspects were conceived during modernity under the influence of the mechanicist/positivist thought, pointing out some of the criticisms to that conception by current researchers. The text indorses a rereading of such concepts in the present time, which may result in important changes in the current curricular organization. It indorses that the rereading of curricular time and space concepts is being stimulated in contexts that include information democratization through "WWW", economic globalization, development of communication and information technologies, expansion of Long Distance Education and, very expressively, the contributions of modern approaches about curriculum and about childhood.

Keywords: Time; Space; Curriculum.

\footnotetext{
* Doutor em Educação pelo Instituto Central de Ciências Pedagógicas (ICCP/Havana/Cuba); Doutor em Engenharia e Gestão do Conhecimento pela Universidade Federal de Santa Catarina (UFSC) e Professor Adjunto na Universidade Federal de Santa Catarina (UFSC). E-mail: juares@ced.ufsc.br
} 


\section{Introdução}

A reflexão apresentada neste artigo é parte de uma pesquisa realizada com o objetivo de aprofundar aspectos dos conceitos de tempo e espaço escolar, como categorias que vêm constituindo a pauta de intensos debates nos ambientes de formação inicial e continuada de professores, nas escolas, nos eventos sobre educação e, obviamente, na literatura.

De modo geral, a produção intelectual resultante do debate em torno da organização espaço/temporal dos currículos, bem como suas implicações na organização dos processos escolares, tanto na modalidade presencial quanto a distância, sinaliza para pelo menos quatro pontos em comum, os quais utilizaremos aqui como referência para a reflexão.

Um primeiro ponto que parece ser convergente entre os estudiosos da temática é o de que a dinâmica da organização curricular da escola contemporânea reflete uma trajetória histórica produzida sob forte influência de metanarrativas que foram sendo pensadas durante a modernidade, desde sua primeira fase, sobretudo, nos campos da ciência, da política e da economia. Outro aspecto, é que as categorias tempo e espaço estão na base da organização curricular da escola e, por essa razão, são elementos fundantes da dinâmica que orienta as rotinas escolares. Um terceiro ponto para o qual convergem os pesquisadores é o de que a redefinição dos processos de organização das atividades curriculares e pedagógicas, pensadas à luz das concepções mais atuais de tempo e espaço, pode favorecer significativamente as oportunidades de aprendizagem e desenvolvimento para estudantes em situação de formação. E, por fim, é comum verificar-se que quando se discute a dinâmica curricular das escolas, as duas categorias aparecem indissociavelmente tratadas, o que significa dizer que elas são entendidas como parte de um mesmo processo que, dialeticamente, se funde na realidade do cotidiano da escola.

À luz da literatura que trata dessa temática, busca-se refletir como as categorias tempo e espaço vêm sendo concebidas e como elas organizam os processos curriculares das escolas, sobretudo no nível da educação básica. Nesse sentido, destacam-se inicialmente algumas das implicações do paradigma da modernidade sobre esse aspecto da organização curricular, para, a partir daí, discutir o que está sendo apresentado como alternativa de mudança, na forma de releitura desses mesmos conceitos, pelos pesquisadores e por algumas escolas. 
O texto traz, portanto, uma reflexão sobre as possibilidades de ressignificação dos conceitos de tempo e espaço como categorias estruturantes do campo do currículo e das ações pedagógicas da escola, e, nelas, a gestão das formas de organização dos espaços e dos tempos para a aprendizagem.

\section{Conceitos de tempos e espaços da organização curricular produzidos durante a modernidade}

Os conceitos de espaço e de tempo são construções sociais e históricas da atividade humana. A ideia que se tem hoje sobre essas categorias na organização curricular, a nosso ver, constitui parte das mediações produzidas nos movimentos de construção histórica da própria modernidade e absorvidos na escola como cultura. A ideia sobre a qual se assenta a percepção atual dessas categorias tem a ver com o conceito mais amplo de tempo e de espaço vigente no paradigma da modernidade.

As transformações sociais vivenciadas pela Europa, sobretudo a partir do século XV, identificadas com o movimento renascentista nos campos da cultura, da política e da ciência e com o fortalecimento da classe burguesa no sistema capitalista repercutiram significativamente sobre as formas de organização das instituições, em geral, e da educação, em particular. Essa espécie de revisão ou reforma do pensamento alterou significativamente aspectos da tradição teológico-idealista e retórico-literária da Idade Média, implicando sobre os modos de organização da sociedade, das instituições e dos indivíduos. Como expressa Macedo (2006), o espaço-tempo do currículo traz, sem dúvida, marcas de uma homogeneidade ditada tanto pela cultura do Iluminismo quanto por uma cultura de mercado, características do pensamento moderno.

Refletindo sobre essa perspectiva, o professor Pedro Goergen (2005) destaca que uma das importantes heranças do início da modernidade para o mundo ocidental foi a ideia de que a mesma lógica que explica os tempos e os espaços da natureza pode explicar os tempos e os espaços do homem. Ou seja, a modernidade pretendeu fazer do tempo e do espaço natural o tempo e o espaço humano. Por essa lógica, obviamente sustentada numa concepção mecanicista de mundo, tempo e espaço pas- 
sam a ser entendidos como categorias racionalizáveis, que se movem em perspectivas lineares e, por isso, passíveis de algum controle.

As referências que sustentaram a abstração desse conceito positivista de mundo pela ciência moderna podem ser encontradas, principalmente, nas formulações de conhecidos pensadores como Bacon (12141294), Copérnico (1473-1543), Bruno (1548-1600), Kepler (1571-1630), Galilei (1564-1642) e Newton (1643-1727). No campo da educação, essa racionalidade foi traduzida, sobretudo, nos trabalhos de Amos Comenius (1592-1670) e Jean Jacques Rousseau (1712-1778), para os quais a natureza é ponto de referência para explicar a vida humana, pois ela sempre ensina aos homens quais são as ordens e os procedimentos mais adequados para suas ações.

Em sua Didática Magna, Comenius deixa isso bem claro quando afirma:

Se levarmos em consideração o que conserva o universo em seu ser com todas as suas particulares individualidades, descobriremos que não é nada mais que a ordem, a disposição de todas as coisas, as primeiras e as últimas, as superiores e as inferiores, as maiores e as menores, as semelhantes e dessemelhantes, segundo o seu lugar, o tempo, o número, a medida e o peso devido e congruente de cada uma. Alguém definiu essa ordem, de modo correto e verdadeiro, como alma das coisas. De fato, o que está ordenado, enquanto mantiver a ordem, conservar-se-á intacto e no mesmo estado; se, ao contrário, a ordem vier a faltar, então começará a languescer, vacilar, ceder e a arruinar-se. Isso é evidenciado por todos os exemplos oferecidos pela natureza e pela arte. (COMENIUS, 2002, p. 123)

Vê-se que Comenius ainda vivia a ambivalência dos conceitos medievais de tempo e espaço (alguém definiu essa ordem) em transição com os conceitos produzidos a partir das influências da ciência moderna (a ideia de ordem natural das coisas). Rousseau, por sua vez, assume uma posição mais definida sobre a sociedade e a educação. A ideia central da educação, em Rousseau, é sua conformidade com a natureza e sua superação pela formação de condutas sociais de moralidade e justiça. Veja-se o que ele diz em Do Contrato social:

A passagem do estado natural ao estado civil produziu no homem uma mudança considerável, substituindo em sua conduta a justiça ao instinto, e imprimindo às suas ações a moralidade que anteriormente lhes faltava. Foi somente então que a voz do dever, sucedendo ao impulso físico, e o direito 
ao apetite, fizeram com que o homem, que até esse momento só tinha olhado para si mesmo, se visse forçado a agir por outros princípios e consultar a razão antes de ouvir seus pensadores. Embora se prive, nesse estado, de diversas vantagens recebidas da Natureza, ganha outras tão grandes, suas faculdades se exercitam e desenvolvem, suas idéias se estendem, seus sentimentos se enobrecem, toda a sua alma se eleva a tal ponto, que, se os abusos desta nova condição, não o degradassem com freqüência a uma condição inferior àquela de que saiu, deveria abençoar incessantemente o ditoso momento em que foi dali desarraigado para sempre, o qual transformou um animal estúpido e limitado num ser inteligente, num homem (ROUSSEAU, 2002, p. 11-2).

Goergen (2005) entende que o que fez Comenius, e de certa forma também Rousseau, foi transferir o novo método desenvolvido pelas ciências naturais para o campo da educação. Especialmente Comenius entendia que para realizar as tarefas educativas com mais eficiência e agilidade era preciso seguir os passos da ciência, ou seja, conquistar e controlar espaço e tempo.

As influências dessa racionalidade científica e técnica, estimuladas intensivamente pelo ideário liberal no modelo capitalista, demarcaram os modos de organização dos espaços/tempos da educação ao longo dos últimos séculos. Nessa perspectiva, o currículo materializou uma organização escolar arquitetada à luz da objetividade e da funcionalidade do conhecimento científico, fortemente marcada pela fragmentação do saber. No caso do Brasil, assim como em outros países de colonização lusoespanhola, a "modelagem" da rotina escolar foi, inicialmente, uma construção jesuítica pensada sob a influência das escolas medievais, derivadas, por certo, das concepções agostiniana e tomista. Elas foram traduzidas nas escolas por via de métodos formais que determinavam uma rígida organização de classes, horários, disciplinas, movimentos e atitudes. Tempos e espaços escolares são entendidos pelos religiosos como racionalidades instrumentais. São colocados a serviço de uma "ordem” que deveria ser estabelecida e, assim, controlada.

É somente no final do século XIX que as orientações de cunho positivista chegam com força no Brasil, período em que as escolas têm seus currículos reformulados, passando-se a adotar disciplinas consideradas científicas em substituição às chamadas literárias. Ainda que tenha havido essa mudança na organização dos currículos, a rotina escolar seguiu enrijecida pelos padrões culturalmente cristalizados. Assim, hábitos assimilados pela rotina escolar, tais como fragmentação dos espaços/tem- 
pos de aprendizagem, objetivação dos procedimentos de ensino, padronização de métodos pedagógicos, agrupamento de alunos por idade ou nível de aprendizagem, fragmentação do currículo por disciplinas, estruturação de horários recortados e rígidos, hierarquização das relações intraescolares, distribuição dos conteúdos escolares por tópicos, determinação de espaços relativamente fixos para cada aluno nas salas de aula, e tantos outros aspectos que marcam a chamada cultura escolar, são construções sociais engendradas desde a Idade Média e reconceitualizadas pela modernidade. Muitos aspectos dessa herança histórica ainda balizam a organização curricular das escolas e servem de orientação para o estabelecimento de suas rotinas.

Ao discutir sobre tempos e espaços da formação e do trabalho pedagógico, Perronoud (2001) afirma que a escola contemporânea continua com o modelo surgido como o mais racional do século XIX. Para ele, cursos recortados em etapas anuais, etapas que devem ser percorridas numa ordem quase imutável, crianças que, pelo princípio da escola obrigatória, entram todas na mesma idade, seguem o mesmo programa e prosseguem cada ano, de uma etapa para outra, até o fim do curso, estudantes escolarizados em estabelecimentos do mesmo tipo, dispersos sobre um território, a partir de uma "carta escolar" que estabelece um lugar mais ou menos obrigatório, estudantes que seguem o mesmo programa, emprego do tempo estruturado por uma grade de horários que atribui para cada semana um tempo fixo, com momentos definidos para cada disciplina, são alguns dos traços mais universais dessa organização que caracteriza o modelo da modernidade.

Sem dúvida, a educação contemporânea, em muitos aspectos, se complexificou, porém a escola não deixou de submeter-se às exigências de uma racionalidade marcada pela técnica, pela funcionalidade, pela objetividade e pela hierarquia. Reproduzindo a lógica da sociedade capitalista, o modelo considerado convencional vem somando visíveis insucessos em termos de resultados no campo da aprendizagem, sobretudo na educação fundamental. A escola, então, como um dos principais espaços de formação humana, reproduz, em sua organização espaço/temporal, racionalidade bastante semelhante àquela produzida na primeira fase da sociedade moderna.

A partir da segunda metade do século XX, com as evidentes ampliação e disseminação da literatura, produzida, sobretudo, no âmbito 
das teorias críticas e pós-críticas, vários pesquisadores têm denunciado essa lógica que concebe tempo e espaço como categorias que são objetivadas e controladas a critério dos interesses de classes.

Stenhouse (1985) diz que a pressão exercida sobre a escola para que mantenha sua própria ordem mediante uma relação hierárquica conduz à gênese de uma ideologia cuja função consiste no controle social. A tradução das estruturas profundas do conhecimento em objetivos de conduta é uma das principais causas da distorção do conhecimento nas escolas. Cambi (1999) afirma que,

Fruto de uma construção histórica e social, a escola moderna foi pensada para atender a formação do homem-cidadão, do homem técnico, do intelectual e não mais a formação do bom cristão, como acontecia na Idade Média. Para tanto, sua estrutura interna precisou também ser revista de modo a se adequar aos objetivos impostos por aquele período. Sua racionalização se deu através da constituição de classes escolares por "classes de idade", através da organização do ensino mediante a disciplina e a prática de exames (CAMBI, 1999, p. 392).

O professor Pedro Goergen (2005, p.13), quando destaca a forte influência da modernidade na formação desses mesmos conceitos na organização da escola contemporânea, recorre a Foucault e registra:

Com seu olhar panóptico, a escola controla, separa, analisa, diferencia e regula os alunos que são configurados, adaptados, enquadrados. O educando não é estimulado a conquistar o seu espaço, a usar o seu tempo, mas a aceitar uma ordem já estabelecida que ele não sabe por quem nem por que foi instituída. Ele não é convocado a desenvolver-se, a expandir-se, mas a aceitar e respeitar o controle, a vigilância dos seus gestos, do seu corpo, de sua mente. O espaço e o tempo são separados e divididos não apenas para otimizar a aprendizagem e menos ainda para libertar, agregar e solidarizar, mas para "vigiar e punir" (Foucault), para segregar e submeter, para transformá-los em células solitárias, acuadas e fracas. O espaço e o tempo na escola são usados como operadores de adestramento que, na leitura de Foucault, se inspiram no modelo militar: A esta penalidade do espaço acrescenta-se a micropenalidade do tempo (horário, atraso, ausência, interrupção) (FOUCAULT, 1989, p. 149).

O professor Miguel Ángel Santos Guerra, na obra Entre bastidores: o lado oculto da organização escolar (2002), apresenta vários argumentos para ilustrar como a escola, na modernidade, tornou-se contraditória e paradoxal no tratamento das questões curriculares e de gestão de suas 
rotinas. Ele destaca que a escola é uma instituição hierárquica que pretende educar na democracia e para a democracia; a escola é uma instituição heterônima que pretende desenvolver sua própria autonomia e a dos indivíduos; a escola é uma instituição com abundantes normas que pretende desenvolver a participação; a escola é uma instituição transmissora que pretende transformar a sociedade; a escola é uma instituição de recrutamento forçado que pretende educar em liberdade e para a liberdade; a escola é uma instituição com concepção epistemológica de caráter hierárquico que pretende desenvolver a criatividade; a escola é uma instituição sexista que pretende educar na diversidade e para a diversidade; a escola é uma instituição fortemente escalonada que pretende desenvolver uma democracia educativa; a escola é uma instituição que alega certa neutralidade, mas colide com uma rede de interesses pessoais e sociais e com disputas ideológicas e axiológicas mais ou menos camufladas.

Denunciando também o modelo da escola moderna com seu convencional currículo, Fernández Enguita (1990) destaca as implicações dessa lógica no processo de formação das pessoas. Diz ele:

Mais do que escrever com uma caligrafia e uma ortografia corretas ou saber calcular raízes quadradas, na escola, aprende-se a levantar-se às oito para se apresentar às nove [...] a seguir rotinas cotidianas e a fazer coisas que não interessam ou aborrecem os alunos; a desenvolver uma jornada de oito horas ou mais; a realizar o próprio trabalho individualmente e a ser avaliado por ele; a que lhe digam o que deve aprender e como deve aprender, tal como num amanhã hipotético dir-lhe-ão o que pode produzir e como deve produzir; a competir com os seus semelhantes e a considerar os seus fracassos como êxitos próprios e vice-versa; a submeter-se a hierarquias e a autoridades; a aceitar que o mundo está dividido entre os que sabem - os professores nas escolas, os patrões e diretores de fábrica - e os que não sabem - os alunos, os operários e os empregados; a movimentar-se por recompensas extrínsecas - hoje, as notas, o ordenado, amanhã - e a desinteressar-se do conteúdo do próprio trabalho etc. (tradução livre do autor) (ENGUITA, 1990, p. 18).

Semelhantes críticas são feitas também por autores como E. P. Thompson (1991), André Petitat (1994), Escolano (1993-4), Nilda Alves (1998), Mayumi Lima (1994), Tyler (1991), Maria Tereza Steban (2006), Viñao Frago (2001) e Veiga-Neto (2002). Para eles, o modo como a escola se organiza hoje tem a ver com o surgimento de uma sociedade industrial que vinculou o tempo natural ao tempo racionalizado do relógio, que rela- 
cionou tempo e espaço da escola com tempo e espaço da fábrica, que vinculou a formação escolar com qualificação para o trabalho.

Não obstante os esforços atuais de pesquisadores, educadores e de alguns sistemas educacionais no sentido de superar esse paradigma, as escolas, de modo geral, continuam tratando tempo e espaço pedagógico como instrumentos racionalizáveis que podem e devem ser controlados, fragmentados, matematizados e hierarquizados, em nome de uma pretensa ordem e de uma idealizada disciplina. Não por acaso, escolas privadas e confessionais, instituições que historicamente se orientaram e ainda se orientam por esses princípios, continuam encontrando espaços importantes e conquistando adesão de boa parcela das famílias.

\section{Uma possível releitura dos conceitos de tempo e espaço na organização curricular para a escola contemporânea}

A expressiva literatura produzida no campo da educação nas últimas décadas e os inúmeros eventos acadêmicos que se propõem discutir questões relacionadas com currículo e trabalho escolar vêm apontando fortes críticas ao modo como a escola se organiza, como ela estrutura seus tempos e espaços pedagógicos e sobre os resultados que ela vem alcançando no âmbito da aprendizagem e da formação.

Certamente, as críticas apontadas na literatura não se limitam a analisar as dificuldades da escola dissociadas de outras questões que envolvem a própria sociedade. Há expressiva quantidade de textos e obras que apresentam discussões sobre as questões da escola em perspectivas mais amplas, geralmente com abordagens interdisciplinares. Essa literatura, independentemente do enfoque que assume, argumenta a favor das possibilidades de autonomia da escola. Acredita que, apesar de seus limites institucionais, a escola tem relativa condição para pensar, projetar e implementar novos modos de organização curricular e pedagógica. Sobretudo os textos que discutem currículo, organização escolar, autonomia e gestão da escola têm contribuído muito nesse aspecto.

Tanto a sociologia da educação quanto outros campos de conhecimento relacionados com o fenômeno educativo estão empenhados em discutir e propor alternativas que visem a melhorar os processos de organização das dinâmicas escolares. A percepção que se tem é de que esta- 
mos em um momento interessante, que aponta para a possibilidade de mudanças tanto conceituais quanto práticas na educação e, consequentemente, na reorganização dos tempos e dos espaços da escola.

Obviamente que a reconceitualização dessas categorias não se dá apenas no âmbito da educação e das ciências que lhe dão sustentação epistemológica. É um movimento que traduz contribuições contemporâneas produzidas em outros campos, como o da física e da filosofia, por exemplo. Nesse âmbito, há um expressivo trabalho de atualização conceitual para essas categorias. Ilustrativamente, podem-se destacar as novas compreensões trazidas pela teoria da relatividade e da mecânica ondulatória; pelas formulações sobre indeterminismos e descontinuidades na gnoseologia de Bachelard; pelas contribuições de Foucault, quando discute poder, sujeito e história; pelos recentes estudos de Bauman sobre espaço/tempo da modernidade; pelas discussões sobre heterogeneidade e qualidade do tempo/espaço em Bergson; pelo conceito multidimensional de tempo e de desterritorialização do espaço em Deleuze e Guattari; pelas contribuições de Derrida sobre o conceito de desconstrução; pelos estudos de Bhabha sobre espaço/tempo na pós-colonialidade; assim como em outras matrizes que buscam romper com a epistemologia do pensamento ocidental eurocêntrico, fortemente marcada na primeira fase da modernidade.

Genericamente, pode-se afirmar que os atuais conceitos de tempo e espaço como categorias filosóficas formam parte, como conteúdo, dos complexos debates entre as concepções científicas mais clássicas e os conceitos de um novo espírito científico ${ }^{1}$ do século XX, dos atuais debates entre modernidade e pós-modernidade, dos debates entre as matrizes teóricas consideradas como universalizantes e as matrizes da diferença, do hibridismo e da desconstrução, entre o pensamento da matriz hegemônica eurocêntrica e o pensamento de uma nova cultura política pós-colonial.

Dadas a especificidade e as limitações deste artigo, serão destacadas tão-somente algumas das características que marcam a atual fase do debate, no contexto brasileiro, dando-se relevância às contribuições que a literatura e os movimentos organizados em torno da educação oferecem para a releitura dos conceitos de tempo e de espaço na organização curricular da escola contemporânea.

Todavia, antes de apresentar as características, destacamos três aspectos que, a nosso ver, marcam a educação atual e, consequentemen- 
te, os modos de organização curricular das escolas. O primeiro deles é que a contemporaneidade ainda não abandonou os conceitos mecanicistas e naturalistas de tempo e espaço produzidos na primeira fase da modernidade. O segundo refere que parte dos educadores se apropria de um discurso relativamente novo, mas, na prática, continua atrelado a uma racionalidade técnica e instrumental, cristalizada nos últimos séculos pela sociedade ocidental. Um terceiro aspecto, que decorre dos dois primeiros, é que o processo de mudança ainda está essencialmente no plano conceitual, portanto, de construção de possibilidades e que, por isso, somente em pequena medida encontra ressonância na ação da escola.

De qualquer forma, as condições para a mudança estão relativamente postas. Atualmente, há maior liberdade para que os sistemas educacionais reestruturem suas redes. A legislação, no que concerne ao campo curricular e pedagógico, está mais flexível. As agências formadoras buscam assimilar as contribuições teóricas mais recentes e trazem esse debate para o âmbito de seus currículos. As tecnologias estimulam experiências significativas. O campo do debate em torno das questões da educação e da escola amplia-se visivelmente. Os processos de formação continuada vêm auxiliando as escolas em seus planejamentos pedagógicos e na ressignificação de suas práticas.

Vive-se na educação, portanto, um movimento de transição, quando velhos conceitos coexistem com iniciativas que desafiam um modelo mais tradicional, mas que ainda não encontram sustentação suficiente para uma transformação mais efetiva da realidade.

As fortes expansão e democratização da informação via WWW, a globalização econômica e o vertiginoso crescimento das tecnologias da informação e comunicação (TICs) são fenômenos que, indiscutivelmente, repercutem nas relações econômicas, culturais e políticas da sociedade global, com implicação direta nos modos como as instituições educativas pensam e organizam suas dinâmicas. São processos complexos que têm a ver com as questões curriculares e que demandam novos conceitos para as categorias tempo e espaço.

Octavi Ianni (1998) considera que os espaços e os tempos da sociedade globalizada estão cada vez mais desterritorializados e interconectados e, por isso, interdependentes. Com a sociedade global mediada pelas redes virtuais de informação e de comunicação, os lugares já não são tão fixos e os tempos estão ainda mais relativizados. 
Com a ciberespacialização ${ }^{2}$, sobretudo do conhecimento e da informação, o aspecto determinante tanto da organização curricular quanto das experiências pedagógicas do ensinar e do aprender não é mais a materialidade e a formalidade do espaço da sala de aula, tampouco o tempo linear definido para cada disciplina. O processo do ensinar e do aprender já não se encontra exclusivamente condicionado a esse ambiente, num tempo determinado e por um currículo predefinido. Ainda que a sala de aula e a organização dos tempos pedagógicos continuem sendo importantes para o desenvolvimento dessas atividades, surgem alternativas que, a princípio, respondem bem às demandas do momento.

A evidente expansão da literatura que discute educação a distância e a consequente ampliação da oferta dessa modalidade no mundo todo representam bons exemplos desse movimento de mudanças. Embora não caiba aqui discutir as repercussões das atuais formas de educação virtual ou a distância em termos de resultados de aprendizagem, vale destacar que elas existem e que sua rápida expansão afeta as formas convencionais de ensinar e aprender.

Ao se tomar como pressuposto a tese de que a aprendizagem é um fenômeno ao mesmo tempo individual e social, que se produz pelo compartilhamento e pelo diálogo entre sujeitos como processos de apropriação de significados, fica evidente que a efetividade da ação educativa está mais relacionada com condições subjetivas de interlocução que os sujeitos elaboram com outros sujeitos e com o mundo do que com construções de currículos lineares ou com formas engessadas de organização dos tempos e dos espaços de aprendizagem propostos objetivamente pelos atuais currículos escolares.

Nessa concepção, a dimensão espaço/tempo de aprendizagem passa a ser essencialmente a de interação do(s) sujeito(s) com as diferentes formas de comunicação e de aproximação com a realidade e com o conhecimento. Essencialmente, importa menos a presença física do aluno na sala de aula ou em qualquer outro ambiente físico por determinado tempo. Importa sim que se garanta o acesso dos estudantes às diversas formas de apropriação e socialização significativa da informação e do conhecimento.

A espacialidade e a temporalidade dos processos de aprendizagem diferem da espacialidade e da temporalidade formal e cronológica que orienta e define o ritmo da sociedade e da natureza. Os tempos e os 
espaços da aprendizagem têm mais a ver com os ritmos não lineares da subjetividade e com os significados das experiências humanas do que com a adequação aos padrões formal e previamente determinados.

No âmbito da aprendizagem, o tempo que transcende o kronos ${ }^{3}$ é o das relações. É kairós, o tempo das vivências que dá significado aos acontecimentos, atravessando a temporalidade cotidiana. É, portanto, um movimento aleatório, inesperado e expressivo da existência, não apreendido pelo planejamento racional, porque é imprevisível (SOUZA; CARDOSO, 2008). E o espaço, que transcende o "ambiente físico", é o que se converte em lugar com seus significados, representações, valores e estímulos. Como dizia Paulo Freire, o espaço retrata uma relação pedagógica.

$\mathrm{Na}$ obra Currículo, espaço e subjetividade: a arquitetura como programa, Frago e Escolano (2001) fazem uma interessante reflexão sobre a dimensão simbólica dos espaços educativos. Para eles, todo espaço é um lugar percebido e essa percepção é um processo cultural e ideológico de representações. Toda linguagem arquitetônica expressa, além de uma ordem construtiva, um sistema de intenções, valores e discursos, enfim, um verdadeiro jogo de simbolismos. Portanto, o espaço jamais é neutro, ele sempre educa. Para discutir a questão dos espaços subjetivos presentes na arquitetura escolar, Escolano (2001) parte da concepção de que o espaço escolar expressa e reflete determinados discursos, além de representar um elemento significativo do currículo, sendo uma fonte de experiência e de aprendizagem.

Ainda sobre a dimensão espacial da atividade educativa, cabe destacar o entendimento da prof ${ }^{a}$ Maria Isabel Cunha (2008). Ela diz que é a dimensão humana que pode transformar o espaço em lugar. O lugar se constitui quando atribuímos sentido aos espaços, ou seja, reconhecemos sua legitimidade para localizar ações, expectativas, esperanças e possibilidades. Quando se diz "esse é o lugar de", extrapolamos a condição de espaço e atribuímos um sentido cultural, subjetivo e muito próprio ao exercício de tal localização. Os lugares extrapolam uma base física e espacial para assumir uma condição cultural, humana e subjetiva. Entram em jogo as representações que os sujeitos fazem dos lugares e o sentido que atribuem aos mesmos (CUNHA, 2008, p. 184).

Nessa perspectiva, a escola deve constituir-se, portanto, de ambientes vivos com diferentes representações, sentidos e significados. Sua organização espaço/temporal deve considerar a pluralidade de vozes, 
de concepções, de experiências, de ritmos, de culturas, de interesses, etc. A escola, por seu currículo e por sua dinâmica, deve conter em si a expressão da convivialidade humana, em toda a sua complexidade.

Não se trata, pois, de abandonar a dimensão do tempo cronológico e dos espaços formais na organização da escola. Trata-se de reconhecer e considerar que cada sujeito tem seu ritmo próprio de aprendizagem e, portanto, um modo singular de pensamento, movimento e ação e que essa aprendizagem só ganha sentido na relação que esse sujeito estabelece com o outro, com o conhecimento e com o mundo. À escola cabe o papel de integrar, por intermédio de sua dinâmica curricular e pedagógica, os tempos e os espaços individuais aos coletivos.

Para Nóvoa (2001) e Popkewitz (1998), os tempos e os espaços devem ser vistos como dinâmicas mais fluidas, com espessuras e tessituras que nos permitam viver diferentes temporalidades sobrepostas e com espaços não mais limitados por suas margens físicas. São espaços e tempos representacionais, ideológicos, culturais, linguísticos, que produzem identidades, diferenças, relações, sentimentos, etc.

Avançar na compreensão de currículo como categoria técnica e instrumental (derivada da concepção cartesiana) ou como uma categoria puramente sociológica (derivada, sobretudo, da concepção crítica) constitui um dos principais desafios que se apresentam no campo da educação ${ }^{4}$. A nosso ver, a releitura dos conceitos de tempo e espaço da escola passa pela necessária releitura dessas concepções de currículo. As discussões que estão em curso e que incluem novas questões ao tema do currículo, tais como cultura, gênero, diferença, identidades, raça, interdisciplinaridade, etc., estão auxiliando nesse sentido.

Atualmente, algumas escolas, inspiradas em abordagens atuais que envolvem essas discussões, buscam certa "reinvenção dos tempos e dos espaços pedagógicos", flexibilizando seus currículos e imprimindo outras dinâmicas ao cotidiano, na tentativa de valorizar as singularidades dos ritmos de aprendizagem e de apropriação dos saberes com mais sentido e significado. São ainda iniciativas isoladas, mas que cumprem papel importante na direção da mudança.

Outra característica que vem marcando esse momento no campo do currículo, com forte implicação sobre as categorias tempo/espaço, é a intensificação do debate sobre o tema infância e aprendizagem. Autores ${ }^{5}$ que discutem essa temática assumem que as crianças 
precisam ser respeitadas como sujeitos de direito em suas singularidades, suas diferenças de cultura, de história e de experiências. $\mathrm{O}$ apelo feito por esses pesquisadores é para que as escolas capacitem seus educadores, repensem seus processos pedagógicos, reorganizem suas dinâmicas e reestruturem seus ambientes de aprendizagem.

É convergente entre pesquisadores e educadores a proposta de uma escola mais aberta, com currículo flexível, que considere as diferentes formas de inserção da criança na realidade social, que compreenda a existência e a manifestação das diferentes infâncias decorrentes das inúmeras realidades sociais vivenciadas pelas crianças em sua individualidade, enfim, que lide bem com diferentes linguagens, manifestações infantis, repertórios de vivências e expectativas. Como destaca Lima (1989, p. 30), ao discutir a questão dos ambientes para a aprendizagem infantil, afinal, "para a criança existe o espaço-alegria, o espaço-medo, o espaço-proteção, o espaço-mistério, o espaço-descoberta, enfim, os espaços de liberdade ou de opressão".

No âmbito dos estudos pós-coloniais, Homi Bhabha (1998) defende que o lugar e o tempo da infância constituem um entre-lugar e um entre-tempo. Ele utiliza as expressões para afirmar que a infância é

O espaço intersticial entre dois modos - o que é consignado pelos adultos e o que é reinventado nos mundos de vida das crianças - e entre dois tempos - o passado e o futuro. É um lugar, um entre-lugar, socialmente construído, mas existencialmente renovado pela ação coletiva das crianças. Mas um lugar, um entre-lugar, pré-disposto nas suas possibilidades e constrangimentos pela História. É, por isso, um lugar na História (BHABHA, 1998).

É notória a contribuição dos trabalhos desenvolvidos no âmbito da sociologia da infância e dos estudos curriculares focados nas questões culturais e da diferença para essa releitura dos conceitos de tempo e espaço.

Cabe destacar que parte das contribuições dos autores que discutem infância e aprendizagem tem sido incorporada nos debates sobre educação para todo o ensino fundamental. As teses de que a escola deve respeitar os tempos da criança, valorizar a ludicidade e o jogo nas atividades de aprendizagem, perceber o movimento e a corporeidade como manifestações significativas no processo de ensino e considerar as experiências do mundo nos espaços vivido, refletido e concebido pela criança 
são alguns postulados assumidos pela educação infantil e que aos poucos são introduzidos nas demais etapas da educação básica.

Sustentadas por concepções que defendem uma espécie de epistemologia da prática ${ }^{6}$, surgem algumas alternativas de reorganização do currículo escolar na tentativa de ressignificar as dinâmicas no cotidiano. Ainda que essas iniciativas ${ }^{7}$ sejam isoladas e, em alguns casos, tenham certo interesse político, são experiências que desafiam os modelos tradicionais e, por isso, contribuem significativamente para o debate no nível mais amplo.

\section{Considerações finais}

Não resta dúvida de que a modernidade descrita por Foucault (1989), Deleuze (2006) e Bauman (2007) como uma sociedade disciplinar ou normalizadora continua influenciando decisivamente as formas de organização do currículo e orientando a distribuição dos tempos e espaços da escola na contemporaneidade.

Todavia, em face do que apresenta a literatura, é possível afirmar que vivemos um tempo de crise da educação formal, caracterizada por certo esgotamento do modelo moderno de organização da escola e pelo evidente insucesso verificado nos resultados da aprendizagem. A contemporaneidade, portanto, nos convoca tanto para uma releitura dos conceitos de escola que fabricaram a modernidade, quanto para a releitura dos conceitos de modernidade que fabricaram a escola - na expressão de Veiga-Neto (2002).

Não obstante a força das influências do pensamento moderno sobre as questões curriculares atuais, percebe-se que os complexos movimentos sociais, econômicos e políticos que marcaram o final do século XX e continuam marcando esse início do século, associados ao expressivo desenvolvimento na área de tecnologia da informação e comunicação, estão possibilitando novas alternativas no campo da educação, momento em que os sistemas e as escolas podem, de várias formas, reconceituar e ressignificar seus processos educativos e, neles, as formas de gestão dos tempos e espaços curriculares.

É inegável o trabalho atual de pesquisadores, gestores e educadores no sentido de transformar o modelo de escola ainda vigente a partir da releitura dos conceitos curriculares de tempo e espaço. 
Esse início de século, mais expressivamente, tem sido marcado por orientações nessa direção, principalmente por trabalhos de pesquisadores que discutem o currículo na perspectiva pós-estruturalista ou póscrítica que aprofundam questões importantes como gênero, cultura, identidade, ética, diferença, etc.

Nessa mesma direção, aparecem algumas iniciativas do poder público e da própria iniciativa privada inspiradas nos conceitos de pluralidade de concepções pedagógicas, gestão democrática e de liberdade de organização curricular, trazidos pela atual LDB. Essa espécie de "abertura" para o currículo tem estimulado estados e municípios a elaborar e implementar novas propostas curriculares para suas redes de ensino.

Antônio Flávio Moreira (2000) destaca que, apesar das limitações e do controle estatal, essas iniciativas abrem novos espaços para a visão de currículo que o concebem como instrumento de comunicação entre teoria e prática, como expressão da função socializadora e cultural da escola, como campo de desenvolvimento de alunos e docentes, como campo de conflitos e de alianças que se expressam em decisões coletivamente tomadas.

Talvez mais difícil do que produzir e legitimar outra lógica para reorientar os tempos e os espaços curriculares da escola contemporânea seja a tarefa de desconstruir os conceitos historicamente postos. 


\section{REFERÊNCIAS}

ALVES, Nilda. O espaco escolar e suas marcas. Rio de Janeiro: DP\&A, 1998.

BAUMAN, Zygmunt. Tempos líquidos. Trad. Carlos Alberto Medeiros. Rio de Janeiro: Jorge Zahar, 2007.

BHABHA, Homi K. O local da cultura. Belo Horizonte: Editora UFMG, 1998.

CAMBI, Franco. História da pedagogia. São Paulo: Editora Unesp, 1999.

COMENIUS, J.A. Didática Magna. Trad. Ivone Castilho Benedetti. São Paulo: Martins Fontes, 2002.

CUNHA, Maria Isabel da. Os conceitos de espaço, lugar e território nos processos analíticos da formação dos docentes universitários. Revista Educação UNISINOS, v. 12, n. 3, set.-dez. 2008.

DELEUZE, Gilles. Diferença e repetição. Rio de Janeiro: Graal, 2006.

ENGUITA, Fernández. La cara oculta de la escuela. Educación y trabajo en el capitalismo. Madrid: Siglo XXI de España Editores, 1990.

ESCOLANO, Agustín. La arquitectura como programa. Espacio-Escuela y currículum in Historia de la educacion. Salamanca: Edições Universidade de Salamanca, 1993-4.

FOUCAULT, Michel. Vigiar e punir: a história da violência nas prisões. Petrópolis: Vozes, 1989.

GOERGEN, Pedro L. Espaço e tempo na escola: constatações e expectativas. FÓRUM PERMANENTE DE DESAFIOS DO MAGISTÉRIO, Campinas. Anais do... abril, 2005.

GUERRA, Miguel Ángel Santos. Entre bastidores: o lado oculto da organização escolar. Porto, Portugal: Asa, 2002.

IANNI, Octávio. A sociedade global. Rio de Janeiro: Civilização Brasileira, 1998.

LEVY, Pierre. Cibercultura. São Paulo: 34, 1997.

LIMA, Mayumi Souza. A cidade e a criança. São Paulo: Nobel, 1989.

LIMA, Mayumi Souza. A importância da qualidade do espaço na educação das crianças. Criança, n. 27, 1994.

MACEDO. Elizabeth. Currículo como espaço-tempo de fronteira cultural. Revista Brasileira de Educação, v. 11, n. 32, maio/ago. 2006.

MOREIRA, Antônio Flávio. Propostas curriculares alternativas: Limites e avanços. Revista Educação e Sociedade. Campinas: v. 21, n. 73, dez. 2000.

NÓVOA, Antônio. Tempos da Escola no Espaço Portugal-Brasil-Moçambique: Dez Digressões Sobre um Programa de Investigação. Currículo sem Fronteiras, v. 1, n. 2, p. 131150, jul./dez. 2001.

PELBART, Peter Pál. O tempo não-reconciliado: imagens do tempo em Deleuze. São Paulo: Perspectiva/Fapesp, 1998.

PERRENOUD. Fhilippe. Espaços-tempos da formação e organização do trabalho Disponível em: <http://www.unige.ch/fapse/SSE/teachers/perrenoud/php_main/php_2001/2001_2 9.rtf>. Acesso em 10/

PETITAT, André. Produção da escola/produção da sociedade: análise sócio-histórica de alguns momentos decisivos da evolução escolar no ocidente. Trad. Eunice Gruman. Porto Alegre: Artes Médicas, 1994.

POPKEWITZ, T.S.; PITMAN, A. e BARRY, A. El milenarismo en la reforma educati- 
va de los años ochenta. Revista de Estudios del Currículum, v. 1, n. 2, 1998.

ROUSSEAU. Jean Jacques. Do contrato Social. Trad. Rolando Roque da Silva. Edição eletrônica, Ed. Ridendo Castigat Mores. Disponível em: <http://www.cfh.ufsc.br/ wfil/contrato.pdf>. Acesso em 18 de Abril de 2009.

SOUZA, Ana M. B.; CARDOSO, Terezinha M. Organização escolar. Florianópolis: UFSC/EAD/CED/CFM, 2008.

STEBAN, Maria Tereza. Sala de aula - dos lugares fixos aos entrelugares fluidos. Braga/Portugal: Revista Portuguesa de Educaşão, v. 19, n. 22, 2006.

STENHOUSE, L. La investigación como base de la enseñaza. Selección de textos por J. Rudduck y D. Hopkins. Madrid: Ediciones Morata, 1985.

THOMPSON, E. P. O tempo, a disciplina do trabalho e o capitalismo industrial. In: SILVA, Tomaz Tadeu (Org.). Trabalho, educação e prática social: por uma teoria da formação humana. Porto Alegre: Artes Médicas, 1991.

TYLER, W. Organización escolar. Una perspectiva sociológica. Madrid: Morata, 1991.

VEIGA-NETO, Alfredo. De geometrias, currículo e diferenças. Educação e sociedade: formação de profissionais da educação, São Paulo, n. 79, p. 163-186, ago. 2002.

VIÑAO FRAGO, Antônio; ESCOLAN Augustín. Currículo. Espaço e subjetividade: a arquitetura como programa. 2 ed. Trad. Alfredo Veiga-Neto. Rio de Janeiro: DP\&A, 2001. 


\section{NOTAS}

1 Expressão adotada por Gaston Bachelard para explicitar as mudanças conceituais do pensamento científico introduzidas pela teoria da relatividade de Einstein.

2 Termo empregado por Pierre Lévy (1997) para designar a virtualização da informação, da comunicação e do conhecimento.

3 Kronos é o tempo do relógio, fixado em horas e minutos e que, na escola, aparece na forma de cronologia que estrutura e organiza o trabalho pedagógico em um programa de ensino e em um calendário. Kronos e Kairós são expressões citadas por Souza e Cardoso (2008), Ferreira e Arco-Verde (2001).

4 Autores como Antônio Flavio Moreira, Tomaz Tadeu da Silva, Henry Giroux, Peter Mclaren e Elisabeth Macedo discutem essa questão com profundidade.

5 Autores consultados: Miguel Zabalza, na obra Qualidade em Educação Infantil (1998); Manuel Jacinto Sarmento e Manuel Pinto, no texto As crianças e a infância: definindo conceitos, delimitando o campo, na obra As crianças, contextos e identidades, de Sarmento e Pinto (1997); e Sônia Kramer em Infância, formação e cultura: uma trajetória de pesquisa (2005).

6 Expressão utilizada por Schõn, D.A. (2000) para discutir a atuação reflexiva dos profissionais da educação.

7 Algumas iniciativas dessa natureza têm sido amplamente divulgadas, como é o caso da Escola da Ponte, em Portugal; as Escolas Parque, em diversos lugares no Brasil; as Escolas Abertas, que buscam integrar-se à comunidade; as Escolas Ativas, sustentadas por uma pedagogia centrada no aluno; os Centros de Educacionais Unificados - CEUs, em São Paulo; as Escolas Plurais de Belo Horizonte; os Centros de Educação de Jovens e Adultos, que adotam metodologias diferenciadas; os Ciclos de Formação, as Escolas de Tempo Integral e tantas outras experiências de organização curricular que buscam reconceituar tempos e espaços de aprendizagem.

Recebido: 25/02/2010

Aprovado: 14/09/2010

Contato: 